\title{
Towards a Local Comprehensive Productive Development Strategy: A Methodological Proposal for the Metropolitan City of Naples
}

\author{
DOI: 10.12776/QIP.V21I1.779
}

Luigi Fusco Girard, Maria Cerreta, Pasquale De Toro

Received: 9 September 2016 Accepted: 30 January 2017 Published: 30 April 2017

\begin{abstract}
Purpose: Identify homogeneous areas for metropolitan cities in order to activate a new governance based on territorial synergistic and symbiotic conditions, thus increasing multidimensional territorial productive processes through spatial planning.

Methodology/Approach: The adopted methodology aimed at structuring a Spatial Decision Support System (SDSS) through three main phases: 1) Selection of criteria and indicators; 2) Statistical implementation procedures; 3) Multicriteria evaluation.

Findings: Experimentation of a useful procedure for supporting the elaboration of strategic metropolitan plans oriented to development strategies for achieving a comprehensive territorial productivity. The obtained results can support the selection of territorial opportunities able to integrate complementary local resources and to activate synergies and symbiosis among them, combining tangible and intangible components.
\end{abstract}

Research Limitation/implication: The research is the first step of a more general study that will be improved with the availability of more data, especially with reference to the industrial and economic processes.

Originality/Value of paper: Proposal of an approach based on a complete integration between Geographic Information System, Multivariate Analysis and Multi-Criteria Evaluation in order to improve the governance of metropolitan cities.

Category: Research paper 
Keywords: metropolitan cities; synergy; symbiosis; multi-criteria evaluation; TOPSIS

\section{INTRODUCTION}

Improving the planning activity of cities towards a higher productivity and giving, at the same time, a human shape to local development, requires a multiplication of the density of relationships between activities, areas, institutions and inhabitants. The capacity to regenerate relationships among productive activities, built environment and rural environment, among people and the physical assets, areas and sites, big cities and towns, people and ecosystems is stressed because the "new paradigm", often evoked today, is based on relationships/bonds that can trigger new synergies and symbioses to activate new chains of value creation. The general model of sustainable regeneration is linked not only to the perspective for extracting the resources and energies needed for new dynamic trajectories through circular processes from the local level, but also to the re-generation of relationships.

Metropolitan cities are characterised by a greater complexity than other cities: every facet is interdependent. A metropolitan city can be considered as a system comprised of many other systems and subsystems: natural/ environmental/ecological; residential; productive/industrial; energy; cultural; economic and social. Many critical issues diffused in metropolitan cities are related to the privatisation and reduction of public spaces, the increasing of informal peripheries, the waste of energy, water, natural resources, the speculative real estate market, the loss of local identity, the lack of accountability and transparency in local governance. Taking into account the above considerations, do we consider metropolitan cities as a problem or as an opportunity? Are metropolitan cities facing dynamic virtuous evolution or are they in a chaotic involutive state? We need effective approaches and tools for a positive answer. The future of metropolitan cities lies in our creative choices and in our creative capacity to identify cooperative win-win solutions, characterised by synergies and symbioses, able to increase metropolitan productivity (Fusco Girard and Di Palma, 2016) through scale economies, agglomeration economies, the territorial value added on time and the synergies economies. Which principles, criteria and tools can be identified for improving the planning activity of metropolitan cities towards a higher productivity and for giving, at the same time, a human shape to local development, multiplying the density of relationships among activities, institutions and local communities?

The model of sustainable regeneration is useful to identify innovative approaches for implementing circular processes. The circular processes are an essential element of metropolitan productivity and, in turn, metropolitan productivity is a key outcome of design and planning. This means considering the economic productivity, but also the social and ecological productivity, including economic and non-economic components. The "comprehensive productivity" is economic, 
ecological and social and also includes non-economic and intangible components for the metropolitan cities' development, playing a key role for a more desirable urban future: a more resilient, inclusive, safe and sustainable future. The key elements of urban attractiveness are human and social capitals from which cooperative capacity, synergies and symbioses arise; the real engine for local development, wellbeing, health and quality of life.

The New 2030 Agenda, approved in New York in September 2015, in the United Nations' Plenary Assembly, identifies 16+1 strategic goals, among whose goal No. 11 concernsmaking cities and human settlements inclusive, safe, resilient and sustainable. Goal No. 12 is about sustainable production and consumption and thus introduces the circular economy approach. All these 2030 Agenda goals (or the majority of them) can be achieved (or not) in the space/cities and, in particular, in metropolitan cities. Urban landscapes reflect local culture and all the challenges of our time. Culture is the key element that can reshape every development perspective.

UN-Habitat is going to reshape the New Urban Agenda as the general agenda for operationalizing principles in a coordinated, integrated and coherent way at different local, metropolitan, regional, and national level. Managing urbanisation is seen more as an opportunity than a problem, to contribute to local economy growth and to increase the urban productivity, creating new employment, in a coevolutive perspective with ecosystems stimulating the perception of the inhabitants' wellbeing.

Circular processes are the characteristic of the natural systems. Circular processes allow the increase in "comprehensive metropolitan productivity" (i.e. economic, social and environmental productivity) (Varlet, 2012), reducing waste and activating three kinds of symbiosis: that between productive and industrial systems, between the city and industrial systems and between the city and the rural territory (Fujita, et al., 2013). The circular urban economy is referred to the comprehensive city economic organisation, through different kinds of symbioses, demonstrating that the circular organisation is able to produce economic convenience, ecological benefits and social benefits, thus enhancing the attractiveness of the city/territory.

In this perspective, urban planning should be able to manage the circular/virtuous processes between the metropolitan city and the rural territory through a systemic approach, evoking the approaches and tools of industrial ecology; the attention to the flow analysis between the city and the territory, to the urban metabolism, to synergistic exchanges between resources flows, due to the spatial/geographic proximity.

The paper moves in an ongoing research context, with a double aim: to develop an operational approach through the case-study and, at the same time, to produce a theoretical-methodological approach for an eventual replicability in analogous problems of homogeneous territorial areas classification. It proposes a comprehensive metropolitan productivity framework for the Metropolitan City of 
Naples. Some relevant and specific indicators are selected to identify local resources and the "homogeneous zones" for activating synergies and symbiosis among the 92 municipalities that form the metropolitan area. Section 2 introduces the concept of comprehensive productivity. Section 3 illustrates the methodology. Sections 4 and 5 present the case study of the Metropolitan City of Naples and first outcomes of the proposed approach and Section 6 offers conclusions.

\section{A COMPREHENSIVE PRODUCTIVITY STRATEGY FOR METROPOLITAN CITIES}

In the typical development processes of metropolitan cities, the commitment that the city must implement to make its organisational structure more efficient becomes crucial to increase wealth production in the direction of sustainable development (Fusco Girard and Di Palma, 2016). Several cities are utilising new tools to face the main challenges emanating from change: environmental decay and ecosystems alteration; intensification of economic competition and growing unemployment. The metropolitan city is the context wherein different economic, social, cultural and environmental factors relate and manage the complexity according to a systemic approach able to balance land resources in order to build a sustainable vision for the future (D'Auria, 2009; D'Auria and Pugliese, 2013). The city - to address the economic, social and environmental change - needs a new model for managing its organisational structure, based on cooperative processes, and thus on synergies and symbioses. In particular, symbiosis becomes the means to rebuild and multiply the bonds at different levels and therefore - thanks to the density of the relationships it generates - makes the system more resilient and less dissipative, while improving its regenerative capacity. The concept of symbiosis has been used in the field of industrial ecology to indicate an organisational system in which different companies, characterised by geographical proximity through an associative approach based on the shared resource management, obtain benefits and competitive advantages from an economic (and also environmental and social) point of view. This is achieved by means of the physical exchange of materials, energy and subproducts (Chertow, Ashton and Espinosa, 2008; Boons and Howard-Grenville, 2011), as well as achieving broader strategies of sustainable industrial development (Chertow, 2007; 2009; Ashton, 2008; 2009; Jensen, et al., 2012).

Recently the concept of symbiosis has been applied to the urban context, by transferring the interactive phenomenon and interdependences, typical of natural ecosystems, to anthropic systems (Fusco Girard, 2014). Some cities have implemented interesting symbiotic processes, considering practices of industrial, urban and territorial symbioses (Fujita, et al., 2013). The focus on different scales of symbiotic processes allows an understanding of how to implement a systemic and integrated approach involving different levels of relationships at the same time, taking into account the various forms of capital. The city is identified as a 
complex system, which requires dynamic and adaptive integrated actions for the construction of synergies between urban, rural and natural areas, and for the circularisation of processes, occurring in natural ecosystems in a similar way. By means of best practices (ex-post evaluation) - as implemented in many port cities such as Rotterdam, Stockholm, Lisbon, Kwinana, Kawasaki, Akita, Aichi, Kitakyushu, etc. (Fusco Girard, 2016) - it is possible to produce empirical evidence about economic, social and environmental advantages of symbiosis, in order to formulate strategies of eco-innovation for future sustainable policies. The evaluation process highlights the benefits derived from the circular economy in terms of wealth production and local employment and the existing links between the promotion of green economy and opportunities to create new jobs. Indeed, symbiotic processes generate a density of links and activities that produce, in their turn, new jobs, providing a significant contribution in terms of social impact and the humanisation of development (Wijkman and Skånberg, 2015; Jacob, Quitzow and Bär, 2015).

Starting from the empirical evidence provided by the evaluation of a selection of cities worldwide, it is possible to highlight that investing in symbiosis activating a process of circularisation, reciprocity and mutuality - determines an increase in the comprehensive territorial productivity from different viewpoints: a) economic, because it allows income production; b) environmental, since it promotes the preservation and protection of cultural and natural heritage; c) social, in terms of employment growth and strengthening the sense of belonging to a place.

In the Italian context, in the last twenty years, metropolitan cities have been losing productivity and attractive capacity in comparison with other European cities, although the potential of the Italian territory is very high, considering that Italy is a large logistic platform in the Mediterranean Sea and is the expression of one of the best cultural landscapes in the world. Many metropolitan cities are port cities and many of them are UNESCO sites.

Italian metropolitan cities are spaces with a high demand concentration for goods and services, where the pressure on natural and environmental capital is very strong, with many consequent risks. In many cases, agglomeration economies are diverted into diseconomies with the overuse of resources, pollution, congestion, discomfort and illness perception. The recent Italian Law No. 56 of April 7, 2014, "Provisions on metropolitan cities, provinces, unions and mergers of municipalities", is a positive initiative to face the multiple difficulties of metropolitan cities and identifies an institutional framework for the activation of strategies for the development of a comprehensive territorial productivity, starting from the awareness of the proximity opportunities for synergies and symbiosis among the different municipalities. 


\section{METHODOLOGY}

The Italian Law No. 56 of April 7, 2014, identifies the metropolitan cities of Rome, Turin, Milan, Venice, Genoa, Florence, Bari, Bologna, Naples and Reggio Calabria, and provides guidelines for the formation of "homogeneous zones" characterised by specific functions and taking into account specific local requirements. It is necessary to identify the characters of the metropolitan cities, considered as territorial institutions that deal with the care of the metropolitan area's strategic development, and the promotion and integrated management of services, infrastructure and communication networks. Unions of municipalities, part of the metropolitan cities, facilitate the implementation of associated functions or local services.

Homogeneous zones, defined as part of the metropolitan strategic plan, reflect the need to improve the effectiveness and efficiency (the productivity) in the definition of policies and projects, and in the delivery of services to citizens, prompting municipalities to operate more increasingly in cooperative form. The establishment of homogeneous zones is an important opportunity to configure shared territorial interests and projects, putting in direct relation metropolitan cities and their municipalities, reorganising and rationalising the existing forms of inter-municipal cooperation and managing associated forms of different services.

A decision-making framework is proposed where Geographic Information Systems (GIS), statistical analysis and Multi-Criteria Evaluation (MCE) techniques are integrated to identify a comprehensive metropolitan productivity framework for the city of Naples and to support the governance change management.

According to the above issues, the proposed Spatial Decision Support System (SDSS) aims to identify the homogeneous zones of the Metropolitan City of Naples, identifying the system of relationships, synergies and symbiosis that can foster cooperation between municipalities, considering the correlation of spatial variables during spatial decision-making. This process uses Principal Components Analysis (PCA) and MCE in order to remove data redundancy among a large set of spatial variables and determine "ideal points" for homogenous zones configuration (Batty and Xie, 1994; Malczewski, 1999; Yeh and $\mathrm{Li}, 2002)$. In the present case-study, PCA is integrated with GIS for the simulation of Dynamic Spatial Units (DSUs), useful for planning purposes and able to describe the synergies and symbiosis among the existing local resources.

\section{THE METROPOLITAN CITY OF NAPLES: A PROPOSAL OF DYNAMIC SPATIAL UNITS}

The Metropolitan City of Naples, in Campania Region, Italy (Fig. 1), was established on January 1, 2015, after the reform of Italian local authorities with 
the Law No. 142/1990, and then established by the Law No. 56/2014. Its capital city is Naples and it includes 92 municipalities.

Naples, with 3,118,149 inhabitants, is the third Italian most anthropic metropolitan area after Milan $(3,707,210)$ and Rome $(3,700,424)$. Moreover, it is in the second class of the European metropolitan areas for population density. It is formed by 92 municipalities, 12 of which count more than 50,000 inhabitants, showing also relevant phenomena of anthropic pressure in limited territorial areas.

Its ageing index outlines a "stable" social structure in which the number of young people is equal to the number of the old one and the mean age is 40 . In the last years, its birth and death trends record a constant mortality growth $(28,482$ deaths in 2014) often due to tumour pathologies. In addition, the murder rate is above the Italian average, and its road unsafety is proved by its road accident mortality rate of $6.90 \%$ (while the national average is $4.65 \%$ ).

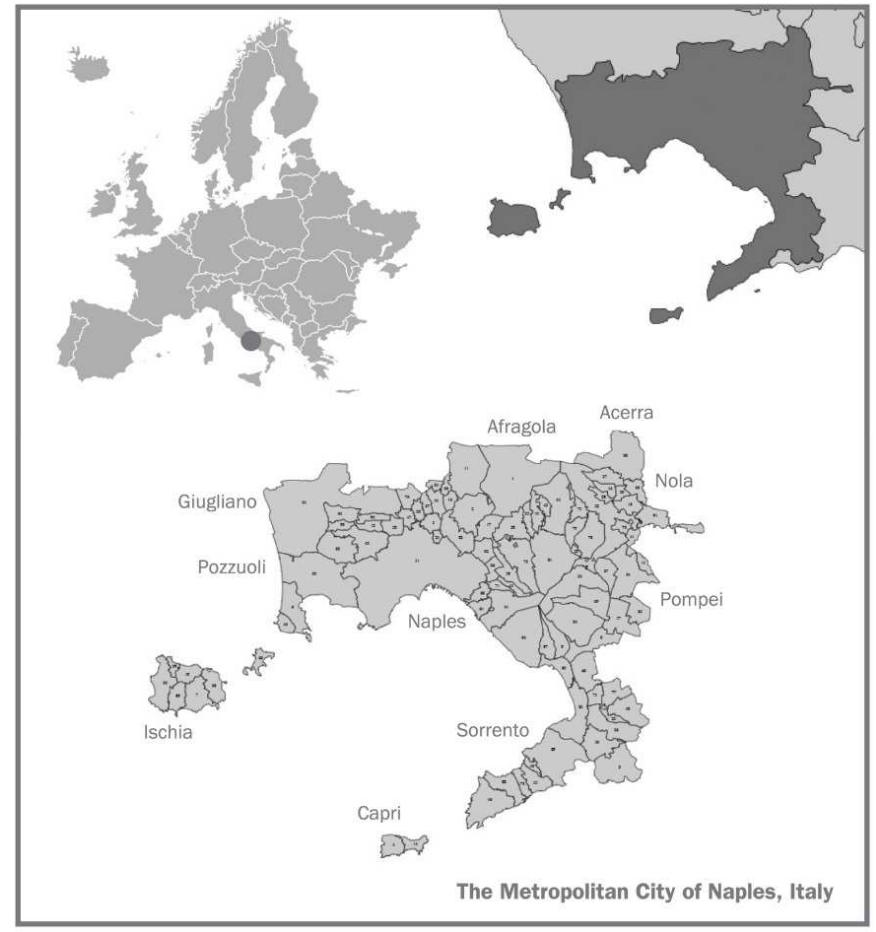

Figure 1 - The study area: the Metropolitan City of Naples (Source: Authors)

Concerning the family affluence, the average disposable gross income $(34,230$ euros) is above the regional one (32,114 euros) but under the Italian one $(40,191$ euros). The mean wage is $19.8 \%$ lower than the Italian average that is 16,924 euros. 
Notwithstanding that many important cultural and landscape assets are present in its territory, the metropolitan area of Naples devotes only $3.5 \%$ to public urban parks, in comparison with the national $5.1 \%$; on average, there are $12.4 \mathrm{~m}^{2}$ of urban green spaces for each inhabitant (vs. the national $32.2 \mathrm{~m}^{2}$ ) and $0.3 \mathrm{~m}^{2}$ of museums every 10,000 inhabitants (vs. 0.8 in Italy).

The Statute of the Metropolitan City of Naples was adopted by the Metropolitan Conference Resolution No. 2, June 11, 2015. Article No. 4 defines the so-called "homogeneous zones" and identifies their features. It highlights that the Metropolitan City of Naples is divided into homogeneous zones for a more harmonious, balanced and functional arrangement of its territory. These areas must be identified through the following factors justifying their common membership: local characters and historical reasons; geo-morphological, naturalistic and landscape contexts; functional relationships and socio-economic frameworks.

Homogeneous zones must be formally established by a specific Resolution of the Metropolitan Council, upon agreement with the Campania Region Government. Each homogeneous zone is formed by the aggregation of contiguous municipalities, in order to include a population of not less than 150,000 inhabitants. A possible derogation, in the perimeter and in the number of inhabitants, must be specifically justified and approved with the agreement of the municipalities involved. Homogeneous zones constitute the optimal environment for both the management and the supply of associated local, municipal and metropolitan services, also through the delegation of functions by the Metropolitan City. In addition, the Metropolitan City economically promotes the joint exercise of functions by the municipalities within the homogenous zones. Their identification is part of a significant decision-making problem: it is essential to propose an aggregation, between municipalities, that may constitute a homogeneous environment with respect to some significant features. At the same time, it is able to activate appropriate synergies and territorial symbiosis oriented to the increase in comprehensive territorial productivity. This will reduce territorial differences/disequilibria.

The adopted methodology (Fig. 2) has allowed the structure of a Spatial Decision Support System (SDSS) and it has be divided into three main phases: 1) Selection of criteria and indicators; 2) Statistical implementation procedures; 3) Multi-Criteria evaluation. In the first phase, we selected a set of criteria and indicators compatible with available data, able to explain constituent components and features characterising the territory of the Metropolitan City of Naples. These have been analysed considering some important criteria: environment, built heritage, quality of life, economy and production, transport, culture and society. These criteria were, in turn, declined by 45 indicators (Tab. 1).

The knowledge of the territory has been structured considering two geographical scales of information selection, in order to analyse existing phenomena through a process of gradual deepening of the constituent components: a) the municipal 
level, considering the specificities of the 92 municipalities forming the Metropolitan City; b) the Census Areas level that identifies the scale of the neighbourhood or information related to aggregates of districts.

The selection of indicators made it possible to describe the main characteristics of the territory, making its specificities explicit. The opportunity to use both municipalities and Census Areas indicators permitted to obtain more detailed information for a certain number of indicators. This is particularly meaningful for the bigger municipalities, as Naples, for which a sub municipal classification was obtained.

The variables information refers to 2011, when the last national Census was taken. Each indicator has been identified with an appropriate synthetic code (Tab. 1), explaining the data coverage (Municipality or Census area) and the positive direction $(\mathrm{max} / \mathrm{min})$. Based on available sources, we created a database collecting information concerning the performance of the 92 municipalities, with respect to each indicator related to the municipal level or the Census Areas. The nature of the database allowed us to structure a spatial information system through the support of a GIS software.

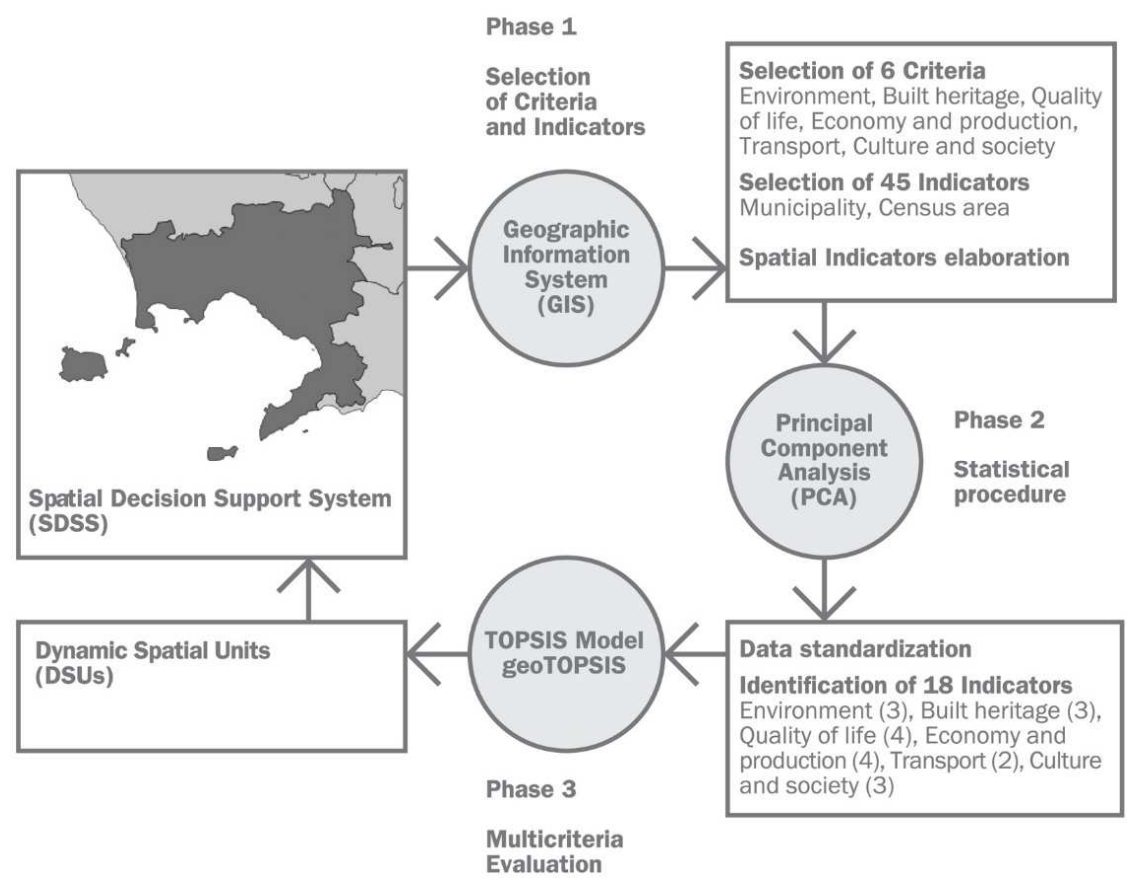

Figure 2 - The methodological framework (Source: Authors)

The available information was made homogeneous with respect to the geographical location, also by means of a spatial representation through 45 thematic maps, corresponding to each indicator. We then transformed each map 
in a raster dataset, where $100 \times 100 \mathrm{~m}$ is the adopted geometric resolution; the map projection is UTM and datum is WGS $198433 \mathrm{~N}$. The information was mapped with respect to administrative borders and classified into five intervals according to an ascending chromatic scale, based on the emerging significance for each of the analysed phenomena.

\section{Table 1 - Criteria and indicators (Source: Authors' processing)}

\begin{tabular}{|c|c|c|c|c|}
\hline Criteria & Indicators & Code & $\begin{array}{c}\text { Data } \\
\text { coverage }\end{array}$ & $\begin{array}{r}\text { Positive } \\
\text { direction }\end{array}$ \\
\hline \multirow[t]{6}{*}{ Environment } & $\begin{array}{l}\text { Percentage of areas of natural interest compared to the total } \\
\text { surface }\end{array}$ & A1 & Municipality & $\max$ \\
\hline & $\begin{array}{l}\text { Percentage of areas subject to urban and environmental } \\
\text { rehabilitation compared to the total surface }\end{array}$ & A2 & Municipality & $\max$ \\
\hline & $\begin{array}{l}\text { Percentage of neglected areas subject to landscape } \\
\text { rehabilitation compared to the total surface }\end{array}$ & A3 & Municipality & $\max$ \\
\hline & Percentage of urban areas compared to the total surface & $\mathrm{A} 4$ & Municipality & $\min$ \\
\hline & Percentage of agricultural areas compared to the total surface & A5 & Municipality & $\max$ \\
\hline & Exposure to volcanic risk (high, medium or low risk) & A6 & Municipality & $\min$ \\
\hline \multirow[t]{6}{*}{ Built heritage } & $\begin{array}{l}\text { Percentage of used buildings compared to the total number of } \\
\text { buildings }\end{array}$ & P1 & Census areas & $\max$ \\
\hline & $\begin{array}{l}\text { Percentage of residential buildings with medium or low } \\
\text { conservation status compared to the total number of residential } \\
\text { buildings }\end{array}$ & $\mathrm{P} 2$ & Census areas & $\min$ \\
\hline & $\begin{array}{l}\text { Percentage of residential buildings compared to the total } \\
\text { number of buildings }\end{array}$ & P3 & Census areas & $\max$ \\
\hline & Population density & $\mathrm{P} 4$ & Municipality & $\min$ \\
\hline & $\begin{array}{l}\text { Percentage of areas of historic, cultural and landscape interest } \\
\text { compared to the total surface }\end{array}$ & P5 & Municipality & $\max$ \\
\hline & $\begin{array}{l}\text { Percentage of areas for public (or public interest) services and } \\
\text { facilities compared to the total surface }\end{array}$ & P6 & Municipality & $\max$ \\
\hline \multirow[t]{10}{*}{$\begin{array}{l}\text { Quality } \\
\text { of life }\end{array}$} & $\begin{array}{l}\text { Number of usable parks and historic gardens per } 10,000 \\
\text { inhabitants }\end{array}$ & Q1 & Municipality & $\max$ \\
\hline & \begin{tabular}{|l|}
$\begin{array}{l}\text { Percentage of community spaces compared to the residential } \\
\text { surface }\end{array}$ \\
\end{tabular} & Q2 & Municipality & $\max$ \\
\hline & Percentage of waste sorting compared to the solid urban waste & Q3 & Municipality & $\max$ \\
\hline & Number of organized crime groups per 10,000 inhabitants & Q4 & Municipality & $\min$ \\
\hline & Number of cancer deaths per 10,000 inhabitants & Q5 & Municipality & $\min$ \\
\hline & $\begin{array}{l}\text { Exposure to air pollution (reclamation, observation or } \\
\text { conservation zones) }\end{array}$ & Q6 & Municipality & $\min$ \\
\hline & Number of contaminate sites & Q7 & Municipality & $\min$ \\
\hline & Elderly index & Q8 & Census areas & $\min$ \\
\hline & Average unitary market price of dwellings & Q9 & Census areas & $\min$ \\
\hline & Average unitary rent price of dwellings & $\mathrm{Q} 10$ & Census areas & $\min$ \\
\hline \multirow[t]{10}{*}{$\begin{array}{l}\text { Economy and } \\
\text { production }\end{array}$} & $\begin{array}{l}\text { Percentage of production areas and industries compared to the } \\
\text { total surface }\end{array}$ & E1 & Municipality & $\max$ \\
\hline & \begin{tabular}{|l|}
$\begin{array}{l}\text { Number of local working units per 10,000 inhabitants } \\
\text { (age 15-64) }\end{array}$ \\
\end{tabular} & E2 & Municipality & $\max$ \\
\hline & $\begin{array}{l}\text { Number of employees in local working units per } 10,000 \\
\text { inhabitants (age 15-64) }\end{array}$ & E3 & Municipality & $\max$ \\
\hline & Average income per capita & E4 & Municipality & $\max$ \\
\hline & Employment rate & E5 & Census areas & $\max$ \\
\hline & Unemployment rate & E6 & Census areas & $\min$ \\
\hline & $\begin{array}{l}\text { Number of agricultural firms compared to the used agricultural } \\
\text { surface }\end{array}$ & E7 & & $\max$ \\
\hline & $\begin{array}{l}\text { Number of biological agricultural firms and/or with typical } \\
\text { products compared to the total number of firms }\end{array}$ & E8 & Municipality & $\max$ \\
\hline & $\begin{array}{l}\text { Percentage of certified firms (EMAS and/or UNI-EN-ISO } \\
\text { 14001) compared to the total number of firms }\end{array}$ & E9 & Municipality & $\max$ \\
\hline & Number of beds in hotels or other types of accommodation & E10 & Municipality & $\max$ \\
\hline
\end{tabular}




\begin{tabular}{|c|c|c|c|c|}
\hline Criteria & Indicators & Code & $\begin{array}{c}\text { Data } \\
\text { coverage }\end{array}$ & $\begin{array}{l}\text { Positive } \\
\text { direction }\end{array}$ \\
\hline & $\begin{array}{l}\text { Average monthly income by visits in museums, monuments } \\
\text { and archaeological areas }\end{array}$ & E11 & Municipality & $\max$ \\
\hline \multirow[t]{4}{*}{ Transport } & $\begin{array}{l}\text { Percentage inhabitants moving daily outside of their resident } \\
\text { municipality compared to the total number of inhabitants }\end{array}$ & $\mathrm{T} 1$ & Census areas & $\min$ \\
\hline & Number of buses per 10,000 inhabitants & $\mathrm{T} 2$ & Municipality & $\max$ \\
\hline & Number of railway stations per $100 \mathrm{~km}^{2}$ of surface & T3 & Municipality & $\max$ \\
\hline & $\begin{array}{l}\text { Number of stops of underground lines, funiculars, cableways } \\
\text { and ferries per } 100 \mathrm{~km}^{2} \text { of surface }\end{array}$ & $\mathrm{T} 4$ & Municipality & $\max$ \\
\hline \multirow[t]{8}{*}{$\begin{array}{l}\text { Culture and } \\
\text { society }\end{array}$} & $\begin{array}{l}\text { Percentage of graduate inhabitants compared to total number } \\
\text { of inhabitants }\end{array}$ & $\mathrm{C} 1$ & Census areas & $\max$ \\
\hline & $\begin{array}{l}\text { Average monthly number of visits in museums, monuments } \\
\text { and archaeological areas }\end{array}$ & $\mathrm{C} 2$ & Municipality & $\max$ \\
\hline & $\begin{array}{l}\text { Number of associations for social, cultural and leisure } \\
\text { promotion per } 10,000 \text { inhabitants }\end{array}$ & $\mathrm{C} 3$ & Municipality & $\max$ \\
\hline & $\begin{array}{l}\text { Number of ethical purchasing groups and networks per } 10,000 \\
\text { inhabitants }\end{array}$ & $\mathrm{C} 4$ & Municipality & $\max$ \\
\hline & Number of no-profit organizations per 10,000 inhabitants & C5 & Municipality & $\max$ \\
\hline & $\begin{array}{l}\text { Percentage of volunteers in no-profit organization compared to } \\
\text { the total number of inhabitants }\end{array}$ & C6 & Municipality & $\max$ \\
\hline & $\begin{array}{l}\text { Number of associations for social assistance and health aid per } \\
10,000 \text { inhabitants }\end{array}$ & $\mathrm{C} 7$ & Municipality & $\max$ \\
\hline & Number of foreign-born people per 100 inhabitants & $\mathrm{C} 8$ & Census areas & $\max$ \\
\hline
\end{tabular}

In the second phase, a statistical procedure was carried out in order to make comparable indicators expressed in heterogeneous units; a process of normalisation of all indicators was performed, using a 0-1 interval scale (Fig. 3).

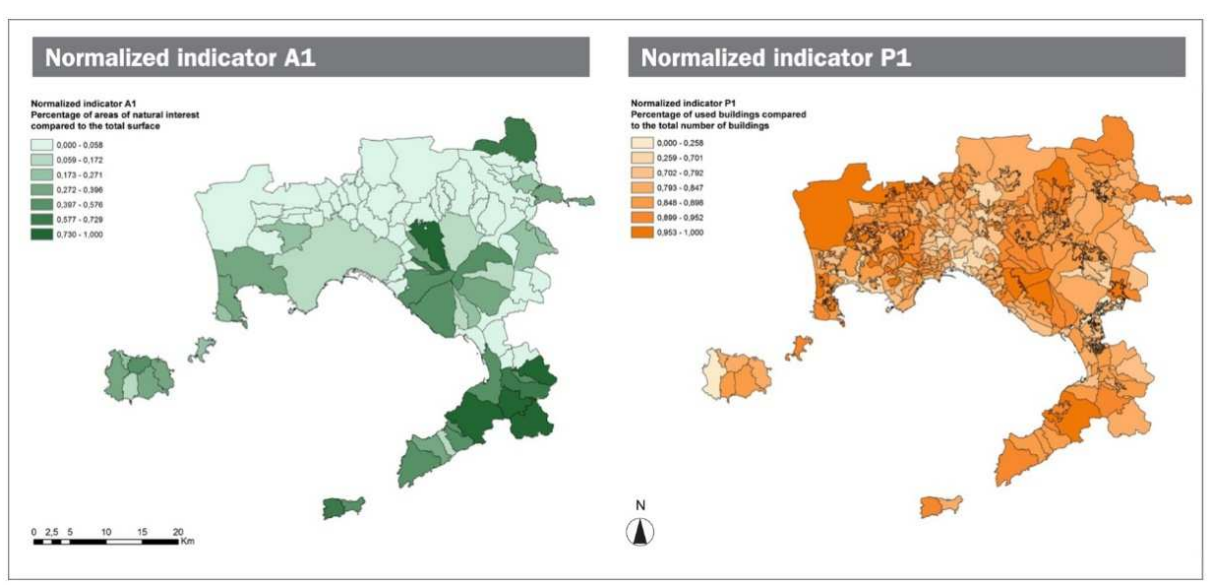

Figure 3 - Example of two different data coverage indicators (Source: Authors' processing)

Afterwards, six Principal Component Analyses (PCA) were carried out (i.e. a PCA for each criterion), using normalised indicators. In particular, Principal Component Analysis (Dewan, 2013; Mago and Dabbaghian, 2014) represents a multivariate analysis that convert a set of observations of possibly correlated variables into a set of values of linearly uncorrelated variables, called "principal components". The number of principal components is less than or equal to the 
number of original variables. This transformation is defined in such a way that the first principal component has the largest possible variance (that is, accounts for as much of the variability in the data as possible) and each succeeding component, in turn, has the highest variance possible under the constraint that it is orthogonal to the preceding components.

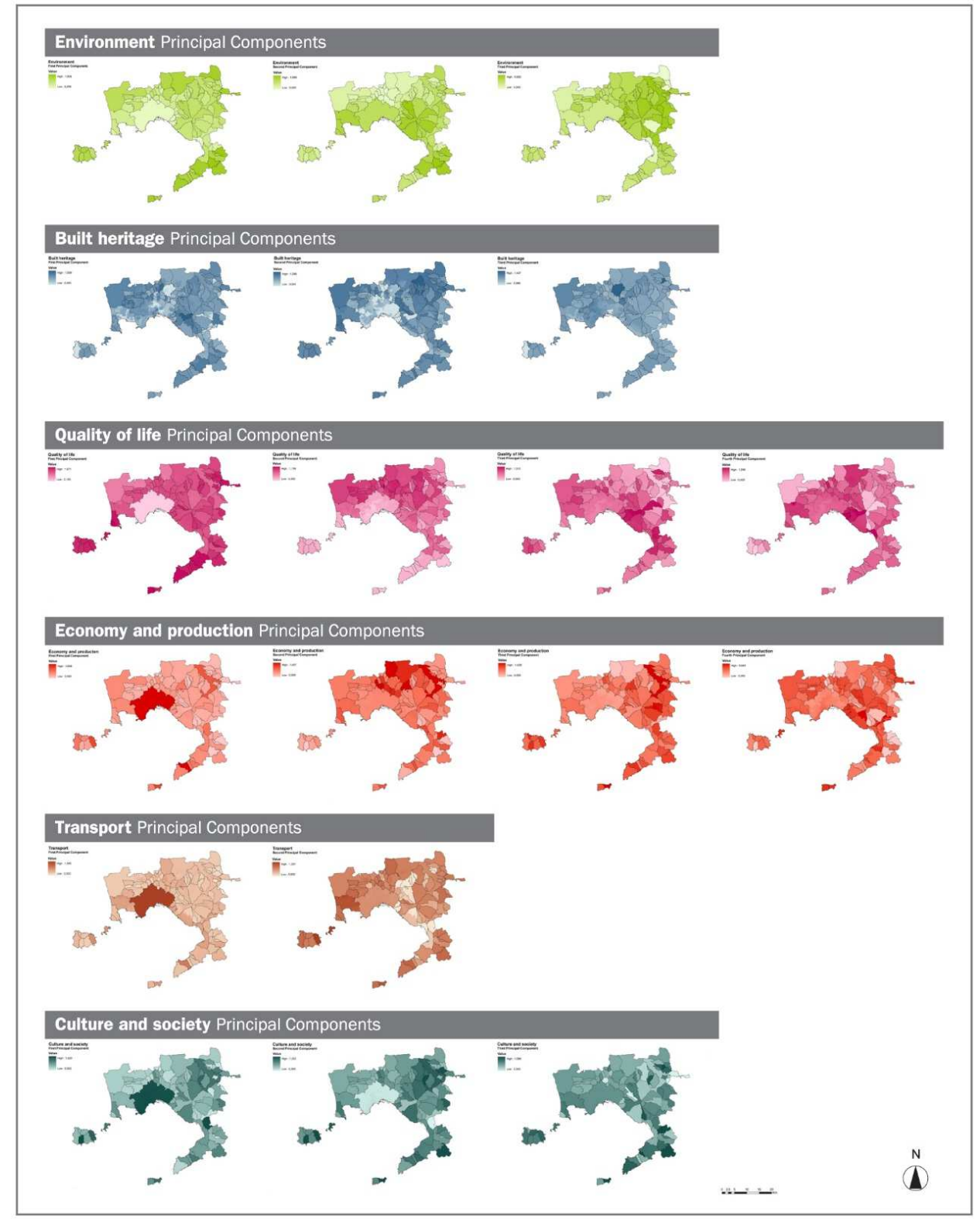

Figure 4 - Principal Components (PC) related to criteria (Source: Authors' processing) 
The resulting vectors are an uncorrelated orthogonal basis-set. PCA is sensitive to the relative scaling of the original variables. A spatial PCA (i.e. using raster layers in GIS) has allowed to identify a set of 18 principal components, explaining about $80 \%$ of cumulative variance: 3 for Environment; 3 for Built heritage; 4 for Quality of life; 4 for Economy and production; 2 for Transport; 3 for Culture and Society (Fig. 4).

The used indicators, synthesized by the Principal Components obtained, explicate the major characteristics of the Metropolitan Area of Naples. The followed can be underlined:

- the most significant areas from environmental quality viewpoint are the Sorrento Peninsula and the islands of Capri and Ischia, as well as the Vesuvio National Park;

- the built heritage, particularly the cultural one, strongly connotes the historic centre of Naples and minor interest towns, e.g. Pozzuoli;

- the quality of life too is better in the Sorrento Peninsula, in the islands and in some minor towns, and anywhere the criminal organizations and the cancer mortality is low;

- economic dynamics are more significant in the city of Naples (that has the higher number of enterprises and workers) or in the Nord-East area of Naples where are the support infrastructures to commercial traffic, e.g. the Nola logistic centre. Whereas Pompei, Sorrento, Naples and the islands are connoted by touristic attractiveness at international level;

- transportation infrastructures are concentrated in the city of Naples, where are various urban underground lines and along the coast, where are railways at metropolitan level;

- the best performances of "culture and society" indicators are found in the city of Naples, full of museums and monuments, and referring to archaeological cultural heritage especially in Pompei and Pozzuoli.

In the third phase, a Multi-Criteria Evaluation was carried out, using the geoTOPSIS algorithm, available in the current VectorMCDA version in QGIS (Rocchi, et al., 2015) that implements the TOPSIS model (Hwang and Yoon, 1981), based on the ideal point approach. Through geoTOPSIS, it was possible to identify some Dynamic Spatial Units (DSUs) for the Metropolitan City of Naples. They represent progressive aggregation of homogeneous areas with respect to which are highlighted territorial synergistic and symbiotic conditions, able to activate multidimensional territorial productive processes (Fig. 5). 


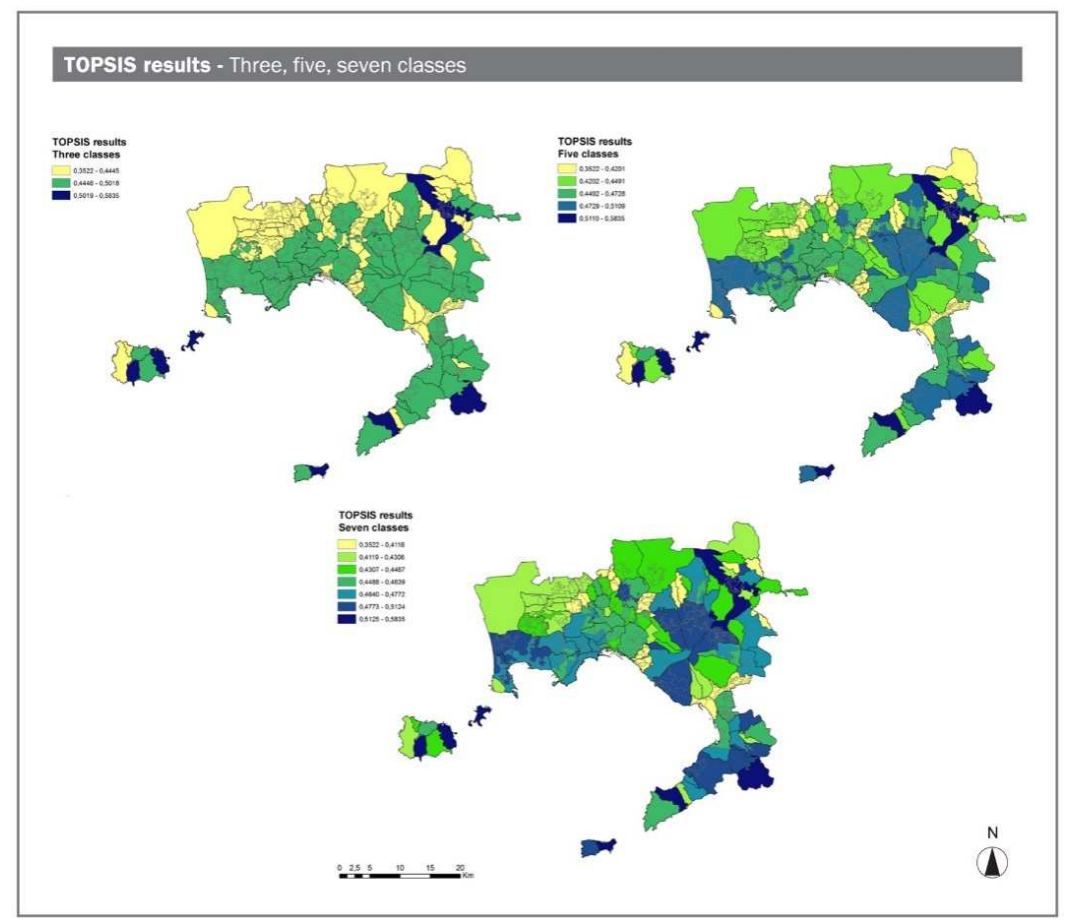

Figure 5 - Dynamic Spatial Units (DSUs)

(Source: Authors' processing)

\section{FIRST OUTCOMES OF THE PROPOSED APPROACH}

Starting from the DSUs it is possible to outline a new geography of the metropolitan area of Naples, identifying the combinations between municipalities in order to establish Homogeneous Zones, reflecting the criteria required by the Statute of the Metropolitan City. Taking into account the fact that each homogeneous zone is to be formed by the aggregation of contiguous municipalities territorially, including a population of not less than 150,000 inhabitants, we propose a possible combination (Fig. 6).

A collection and waste management service (from paper packaging to electrical equipment, plastics, etc.) becomes a necessity within homogeneous zones, representing a continuous challenge for the city of Naples. Furthermore, in these areas, the coordination of the different sectorial policies becomes easier, reducing production/management costs. Starting from the local characteristics, we must build and enhance a common culture between inhabitants and local actors,improving governance as a bottom-up approach, and then improve the quality of life/wellbeing, itself.

In the homogeneous zones, it is easier to proceed to the regeneration of relationships/bonds between social actors and the territory, thus promoting interactive collaborative processes (stimulating a multi-helix approach). 


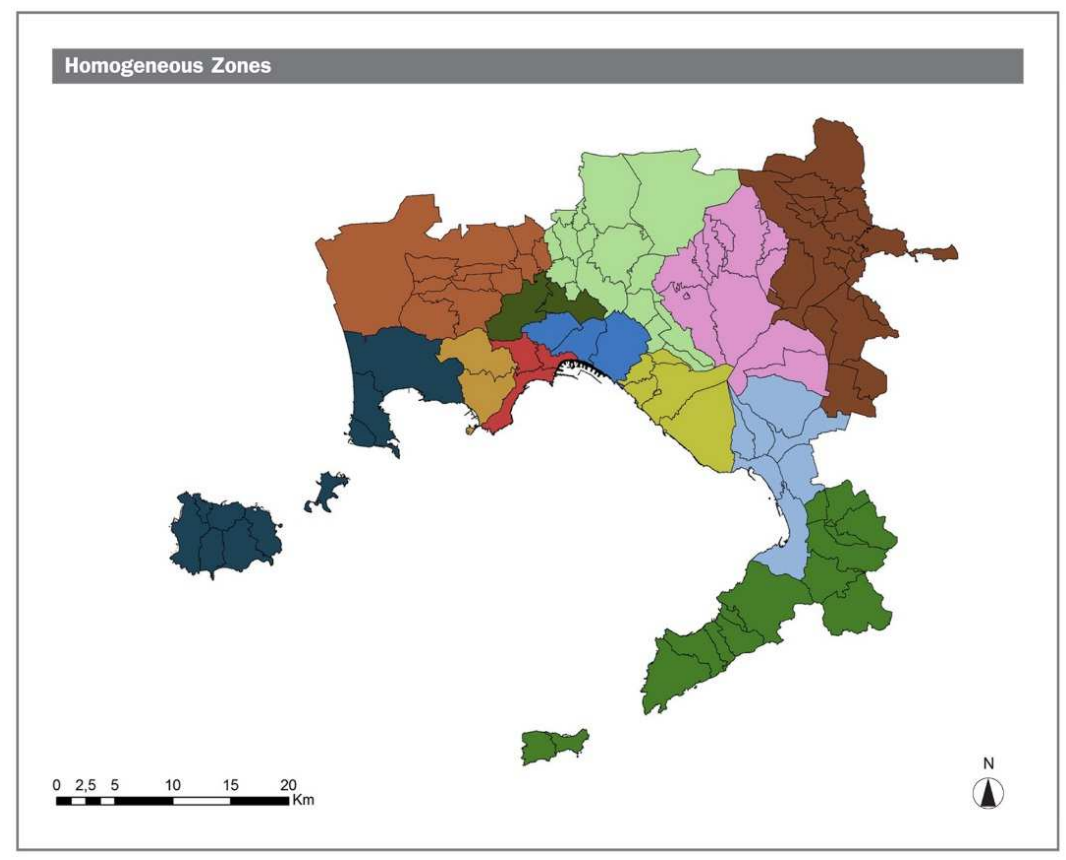

Figure 6-Proposal of Homogeneous Zones for the Metropolitan City of Naples (Source: Authors' processing)

The current lack of useful data did not allow us to elaborate flows/exchanges analysis between the urban zones and the port areas (such as Pozzuoli, Torre del Greco, Torre Annunziata, Naples, etc.), necessary to promote a productive regeneration of processes between territories/cities and ports, and thus activate processes of circular economy (starting from agro-food sector, logistics, shipbuilding, etc.), reducing environmental impacts together with production costs.

The city of Naples has been divided into homogeneous districts that present characteristics strongly knowledgeable for their economic dynamics, historical and landscape values, environmental qualities, human health, etc.

Moreover, we think that results are sufficiently sound over time and therefore there is no need of new data working out in the short term. This is true because in spite of referring mostly to the 2011 Census data, the last ones express and confirm trends already in progress in the previous census of 2001. The resulting classification explicates the characteristics that strongly connote the territorial elements of the metropolitan area of Naples, as already explicated in the previous paragraph. 


\section{CONCLUSIONS}

The Metropolitan City of Naples is an interesting example wherein to implement a methodological approach, able to support the elaboration of the strategic plan oriented to development strategies for improving the comprehensive territorial productivity. The identification of DSUs supports the selection of territorial opportunities able to integrate complementary local resources and to activate synergies and symbiosis among them, combining tangible and intangible components (Cerreta and De Toro, 2012; D'Auria and Monti, 2013).

Starting from the DSUs, it is possible to facilitate the aggregation of municipalities and the awareness of homogenous units, making suitable land available and analysing its development possibilities; implementing a sustainable economic development; protecting and enhancing the natural, historic and cultural environment; ensuring high quality development and efficient use of resources; promoting inclusive and liveable communities. Homogenous zones will outline the background information and characterisation, from a territorial, economic and social point of view; a possible territorial vocation, considering both the history and the future perspectives and actions, policies and projects that can be charged by municipalities in a cooperative/partnership form.

Within each homogeneous zone, it is possible to activate circular processes of mutual cooperation between different actors, as generators of new value creation chains, reducing costs. New productive relationships can be implemented between the different homogeneous zones, valorising differences in a complementary/holistic vision and based on cooperation, thus opening new opportunities for investments in the metropolitan area.

\section{REFERENCES}

Ashton, W.S., 2008. Understanding the organization of industrial ecosystems. Journal of Industrial Ecology, 12(1), pp.34-51.

Ashton, W.S., 2009. The structure, function, and evolution of a regional industrial ecosystem. Journal of Industrial Ecology, 13(2), pp.228-246.

Batty, M. and Xie, Y., 1994. From cells to cities. Environment and Planning B: Planning and Design, 21(7), pp.531-548.

Boons, F. and Howard-Grenville, J. eds., 2011. The Social Embeddedness of Industrial Ecology. Cheltenham, UK: Edward Elgar.

Cerreta, M. and De Toro, P., 2012. Urbanization suitability maps: a dynamic spatial decision support system for sustainable land use. Earth System Dynamics, 3(2), pp.157-171.

Chertow M.R., 2007. "Uncovering” industrial symbiosis. Journal of Industrial Ecology, 11(1), pp.11-30.

Chertow, M.R., 2009. Dynamics of geographically based industrial ecosystems. 
In: M. Ruth and B. Davidsdottir, eds. 2009. The Dynamics of Regions and Networks in Industrial Ecosystems. Cheltenham, UK: Edward Elgar. Chapter 2.

Chertow, M.R., Ashton, W.S. and Espinosa, J.C., 2008. Industrial symbiosis in Puerto Rico: environmentally related agglomeration economies. Regional Studies: The Journal of the Regional Studies Association, 42(10), pp.1299-1312.

D’Auria, A., 2009. Urban cultural tourism: creative approaches for heritagebased sustainable development. International Journal of Sustainable Development, 12(2-4), pp.275-289.

D'Auria A. and Monti, B., 2013. The guardianship of the landscapes between identification and assessment: Ischia and its lost identity. In: Rezekne Higher Education Institution, Society, integration, education: utopias and dystopias in landscape and cultural mosaic: visions values vulnerability, Vol. IV. Proceedings of the International Scientific Conference on Society, Integration, and Education Location. Udine, Italy, 27-28 June 2013. Rezekne, Latvia: PSRI of Rezekne Higher Education Institution, pp.165-176.

D'Auria, A. and Pugliese, S., 2013. The governance of UNESCO cultural landscapes between universal values and local identity: the case of Campania.In: Rezekne Higher Education Institution, Society, integration, education: utopias and dystopias in landscape and cultural mosaic: visions values vulnerability, Vol. V. Proceedings of the International Scientific Conference on Society, Integration, and Education Location. Udine, Italy, 27-28 June 2013. Rezekne, Latvia: PSRI of Rezekne Higher Education Institution, pp.189-200.

Dewan, A.M., 2013. Floods in a megacity: geospatial techniques in assessing hazards, risk and vulnerability. New York: Springer-Verlag.

Fusco Girard, F., 2014. City systems: a new development strategy to promote a new economic paradigm. Human System Management, 33(1-2), pp.35-45.

Fusco Girard, L., 2016. The city and the territory system: towards the "new humanism" paradigm. Agriculture and Agricultural Science Procedia, 8, pp.542551 .

Fusco Girard, L. and Di Palma, M., 2016. The symbiosis as a tool for urban regeneration in the port cities. $B D C, 16(2)$, pp.239-250.

Fujita, T., Ohnishi, S., Liang, D. and Fujii, M., 2013. Eco-industrial development as a circularization policy framework toward sustainable industrial cities. Lesson and suggestions from the eco town program in Japan. BDC, 13(1), pp.35-52.

Hwang, C.L. and Yoon, K., 1981. Multiple attribute decision making: methods and applications. New York: Springer-Verlag.

Jacob, K., Quitzow, R. and Bär, H., 2015. Green jobs: impacts of a green economy on employment. [pdf] Eschborn: Gesellschaft für Internationale Zusammenarbeit (GIZ) GmbH. Available at: $<$ http://www.greengrowthknowledge.org/sites/default/files/downloads/resource/J 
acob,\%20Quitzow,\%20B\%C3\%A4r\%202014\%20Green\%20Jobs_ENGLISH.pdf $>$ [Accessed 2 August 2016].

Jensen, P.D., Basson, L., Hellawell, E.E. and Leach, M., 2012. Habitat suitability index mapping for industrial symbiosis planning. Journal of Industrial Ecology, 16(1), pp.38-50.

Mago, V.K. and Dabbaghian, V., 2014. Computational models of complex systems. New York: Springer-Verlag.

Malczewski, J., 1999. GIS and multicriteria decision analysis. New York: John Wiley \& Sons.

Rocchi, L., Massei, G., Paolotti, L. and Boggia, A., 2015. Geographic MCDA for sustainability assessment: the new tool VectorMCDA. In: EURO (The Association of European Operation Research Societies), 27th European Conference on Operational Research. Glasgow, UK, 12-15 July 2015. Glasgow: EURO.

Varlet, D., 2012.Enjeux, potentialities et contraintes de l'écologie industrielle. Le cas de Dunkerque. Ph.D. Université du Littoral-Côte d'Opale.

Wijkman, A. and Skånberg, K., 2015. The circular economy and benefits for society. jobs and climate clear winners in an economy based on renewable energy and resource efficiency. [pdf] Zurich, $\mathrm{CH}$ : The Club of Rome. Available at: $\quad<$ http://www.clubofrome.org/wp-content/uploads/2016/03/The-CircularEconomy-and-Benefits-for-Society.pdf $>$ [Accessed 2 August 2016].

Yeh, G.O. and Li, X., 2002. Integration of principal components analysis and cellular automata for spatial decision-making and urban simulation. Science in China (Series D), 45(6), pp.521-529.

\section{ABOUT AUTHORS}

Luigi Fusco Girard, Full professor, University of Naples "Federico II", girard@unina.it, via Toledo 402, 80134 Naples, Italy.

Maria Cerreta, Associate professor, University of Naples "Federico II", cerreta@unina.it, via Toledo 402, 80134 Naples, Italy.

Pasquale De Toro, Associate professor, University of Naples "Federico II", detoro@unina.it, via Toledo 402, 80134 Naples, Italy. 